\title{
Optimization of culture conditions for exopolysaccharides production in Rhizobium sp. using the response surface method
}

\author{
Flávia Pereira Duta* \\ Escola de Química \\ Dep. de Engenharia Bioquímica \\ Universidade Federal do Rio de Janeiro \\ Ilha do Fundão, Rio de Janeiro \\ RJ, 21949-900, Brasil \\ Tel: 552125627621 \\ Fax: 552125627667 \\ E-mail: fpduta@hotmail.com
Francisca Pessôa de França*
Escola de Química
Dep. de Engenharia Bioquímica
Universidade Federal do Rio de Janeiro
Ilha do Fundão, Rio de Janeiro
RJ, 21949-900, Brasil
Tel: 552125627621
Fax: 552125627667
E-mail: fpfranca@eq.ufrj.br

Léa Maria de Almeida Lopes

Instituto de Macromoléculas Professora Eloísa Mano Universidade Federal do Rio de Janeiro

Ilha do Fundão, Rio de Janeiro

RJ, 21945-970, Brasil

Tel: 552125627232

Fax: 552125627232

E-mail: lealopes@ima.ufrj.br

Financial support: CNPq (Conselho Nacional do Desenvolvimento Científico e Tecnológico), and CAPES (Coordenação de Aperfeiçoamento de Pessoal de Nível Superior).

Keywords: exopolysaccharides, experimental design, response surface method, Rhizobium sp.

Abbreviations: EPS: exopolysaccharides

HPLC: high performance liquid chromatography

YMA: yeast mannitol agar

The combined effects of the processing parameters for exopolysaccharides production by Rhizobium sp. was studied using the experimental design and response surface methodology. The experiments were carried out using a fermenter with $20 \mathrm{~L}$ capacity, as the reactor. All processing parameters were online monitored. The temperature $\left[(30 \pm 1)^{\circ} \mathrm{C}\right]$ and $\mathrm{pH}$ value $(7.0 \pm 0.1)$ were kept constant throughout the experimental time. As statistical tools, a complete $2^{3}$ factorial planning with central point and response surface were used to study the interactions among three relevant variables of the fermentation process: calcium carbonate concentration, aeration and agitation. The processing parameters setup for reaching a maximum response for exopolysaccharides production was obtained when applying the highest values for calcium carbonate concentration $(1.1 \mathrm{~g} / \mathrm{L})$, aeration $(1.3 \mathrm{vvm})$ and agitation (800 rpm). In addition, the combination of these optimum processing parameters yielded $Y_{\mathrm{P} / \mathrm{S}}(\mathrm{g} / \mathrm{g})=$ 0.35 .

Bacterial exopolysaccharides are extensively used as thickening and gelling agents in a wide range of industrial products and processes due to their structural and physical properties diversity (Copetti et al. 1997; Rinaudo, 2001). The structure, composition and viscosity of the microbial polysaccharides depend on several factors, such as the composition of the culture medium, carbon and nitrogen source, mineral salts, trace elements, type of strain, and fermentation conditions $(\mathrm{pH}$, temperature, oxygen

\footnotetext{
* Corresponding authors
} 
concentration, agitation) (Moreira et al. 1998; WeusterBotz, 2000; Pinto et al. 2002; Duta et al. 2004).

For many microbial species, calcium is essentially required in small amounts: it is essential in maintaining cell wall rigidity, it stabilizes oligomeric proteins and covalently bound protein peptidoglycan complexes in the outer membrane, as well as have a requirement for chemotaxis (Macció et al. 2002).

Table 1. Matrix of the factorial $2^{3}$ planning.

\begin{tabular}{|c|c|c|c|}
\hline Experiments & $\boldsymbol{X}_{\mathbf{1}}$ & $\boldsymbol{X}_{\mathbf{2}}$ & $\boldsymbol{X}_{\mathbf{3}}$ \\
\hline 1 & -1 & -1 & -1 \\
\hline 2 & +1 & -1 & -1 \\
\hline 3 & -1 & +1 & -1 \\
\hline 4 & +1 & +1 & -1 \\
\hline 5 & -1 & -1 & +1 \\
\hline 6 & +1 & -1 & +1 \\
\hline 7 & -1 & +1 & +1 \\
\hline 8 & +1 & +1 & +1 \\
\hline 9 & 0 & 0 & 0 \\
\hline 10 & 0 & 0 & 0 \\
\hline 11 & 0 & 0 & 0 \\
\hline
\end{tabular}

The reach of optimized fermentation conditions, particularly associated to physical and chemical parameters, is of primary and great importance for the development of any process, due to their impact upon its economics and practicability. The diversity of combinatory interactions among medium components, metabolism of cells and the large number of chemical requirements for processing metabolic products, do not allow satisfactory detailed modelling. The one-dimensional search with successive changes on variables conditions is still employed, even trough it is well accepted that it is practically impossible for the one-dimensional search to accomplish an appropriate optimum combination in a finite number of experiments. Single variable optimization methods are not only tedious, but can also lead to misinterpretation of results, especially taking into account that the interaction between different factors is overlooked (Abdel-Fattah et al. 2005). Statistical experimental designs have been used for many decades and can be adopted on several steps of an optimization strategy, such as for screening experiments or searching for the optimal conditions of a targeted response (Kim et al. 2005; Lee and Gilmore, 2005; Nawani and Kapadnis, 2005; Senthilkumar et al. 2005; Wang and Lu, 2005). Recently, the results analyzed by a statistical planned experiment are better acknowledged than those carried out by the traditional one-variable-at-a-time method. Some of the popular choices, applying statistical designs to bioprocessing, include the Plackett-Burman design (Liu et al. 2003; Wang and Lu, 2005) and response surface methodology with various designs (Abdel-Fattah, 2002; Abdel-Fattah and Olama, 2002; Tanyildizi et al. 2005). The response surface methodology is an empirical modelling system that assesses the relationship between a group of variables, which can be controlled experimentally, and the observed response. This methodology is applied mainly both in food science and in the optimization of fermentative processes. It is a 2-level factorial design, where contour plots are generated by linear or quadratic effects of key variables, and a model equation is derived, fitting the

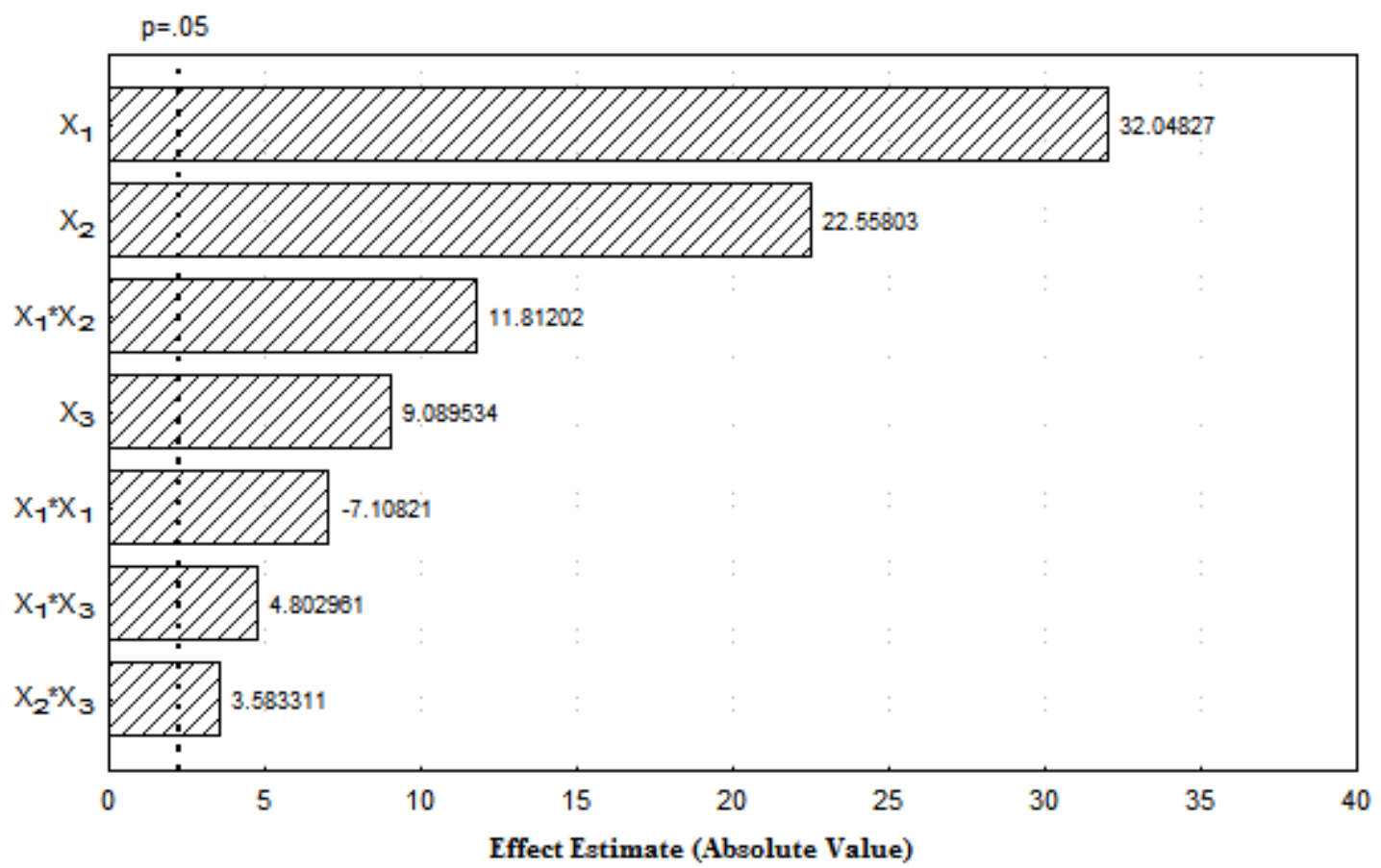

Figure 1. Pareto chart of standardized estimated effects of the different variables tested in the prospective experiment on exopolysaccharides production by Rhizobium sp. The variables tested were: calcium carbonate concentration $\left(X_{1}\right)$, aeration $\left(X_{2}\right)$ and agitation $\left(X_{3}\right)$. The point at which the effect estimates were statistically significant $(p=0.050)$ is indicated by stippled line. 
experimental data to the calculate system's optimal response (Lakshman et al. 2004; Cazetta et al. 2005; Khanna and Srivastava, 2005).

Fast growing rhizobia synthesize different extracellular polysaccharides, like acid exopolysaccharides (EPS) of high molecular weight (Zevenhuizen, 1986). Those microorganisms can also produce neutral glucans, formed by $\beta-1,4$ bonds, which are found as cellulosic microfibrils of low molecular weight (Zevenhuizen, 1986; Breedveld et al. 1990; Jain et al. 1990; Breedveld et al. 1993).

Table 2. The independent variables and their levels for the experimental design with central point.

\begin{tabular}{|l|c|c|c|}
\hline \multirow{2}{*}{ Variables } & \multicolumn{3}{|c|}{ Levels } \\
\cline { 2 - 4 } & $\mathbf{+ 1}$ & $\mathbf{0}$ & $\mathbf{- 1}$ \\
\hline$X_{1}-$ Calcium Carbonate Concentration $(\mathrm{g} / \mathrm{L})$ & 1.0 & 0.8 & 0.5 \\
\hline$X_{2}-$ Aeration $(\mathrm{vvm})$ & 1.3 & 0.8 & 0.2 \\
\hline$X_{3}-$ Agitation $(\mathrm{rpm})$ & 800 & 500 & 200 \\
\hline
\end{tabular}

Many rhizobia stains produced polysaccharides are not found freely dispersed in the medium, but attached upon the microbial cell as an amorphous viscous material. Among these, the curdlana homo-polymer is outstanding, in which the derived sulphated sites show anticoagulant and antithrombosisactivities. Besides, they also present an inhibiting effect against the HIV-1 virus in vitro infection (Jagodzinski et al. 1994). Curdlana sulpho-alkiled sites present anti-tumour activity, inhibiting the development of the Sarcoma tumours 180 (Bohn, 1995).

The present study investigated the relationship among three variables, that is, calcium carbonate concentration, agitation, and aeration, in exopolysaccharide production by Rhizobium sp.

\section{MATERIALS AND METHODS}

\section{Microorganism}

The Rhizobium EQ1 strain was used in the experiments. This was isolated from a variety of beans culture, native from an arid region of the Northeast of Brazil, named as "Caupi". This strain has been kept in yeast mannitol agar (YMA), for several months, being catalogued, after its characterization, at the culture bank of the Biochemical Engineering Department from Federal University of Rio de Janeiro, under the code EQ1.

The microorganism was grown under $(30 \pm 1)^{\circ} \mathrm{C}$ for $48 \mathrm{hrs}$, using laboratory tubes filled with YMA medium. After growth, the cultures were stored at $(5 \pm 1)^{\circ} \mathrm{C}$.

\section{Culture media}

The microorganism stock culture was maintained in modified yeast mannitol agar extract, which presented the following composition $(\mathrm{g} / \mathrm{L})$ : mannitol (10.0); $\mathrm{K}_{2} \mathrm{HPO}_{4}$ (0.1); $\mathrm{KH}_{2} \mathrm{PO}_{4}(0.4) ; \mathrm{MgSO}_{4} .7 \mathrm{H}_{2} \mathrm{O}(0.2) ; \mathrm{NaCl}(0.1)$; yeast extract (0.4); agar (15.0). The medium $\mathrm{pH}$ was adjusted to 7.0 (Jordan, 1984).

The stock culture was used for preparing the inoculum, using $500 \mathrm{~mL}$ Erlenmeyer flasks, containing $100 \mathrm{~mL}$ of the YMA medium free from agar. Incubation was carried out in a rotary shaker at $200 \mathrm{rpm}$ and $(30 \pm 1)^{\circ} \mathrm{C}$, for $48 \mathrm{hrs}$, with the cells in the final of exponential growth phase.

The exopolysaccharides production assays were carried out using a similar culture medium, where the YMA medium was: supplemented with manganese ions $\left(\mathrm{MnCl}_{2} .4 \mathrm{H}_{2} \mathrm{O}\right.$ $0.12 \mathrm{~g} / \mathrm{L}$ ); free from agar; and the calcium carbonate concentration ranged in accordance to the experimental design $\left(\mathrm{CaCO}_{3}\right.$ 0.5-1.0 g/L). The $\mathrm{pH}$ of this medium was adjusted to 7.0 by the addition of $\mathrm{NaOH}(50 \%$ w/v). All culture media were sterilized at $121^{\circ} \mathrm{C}$ for $20 \mathrm{~min}$.

The inoculation of the production medium was made in order to obtain an average cells concentration of $0.77 \pm$ $0.02 \mathrm{mg} / \mathrm{mL}$.

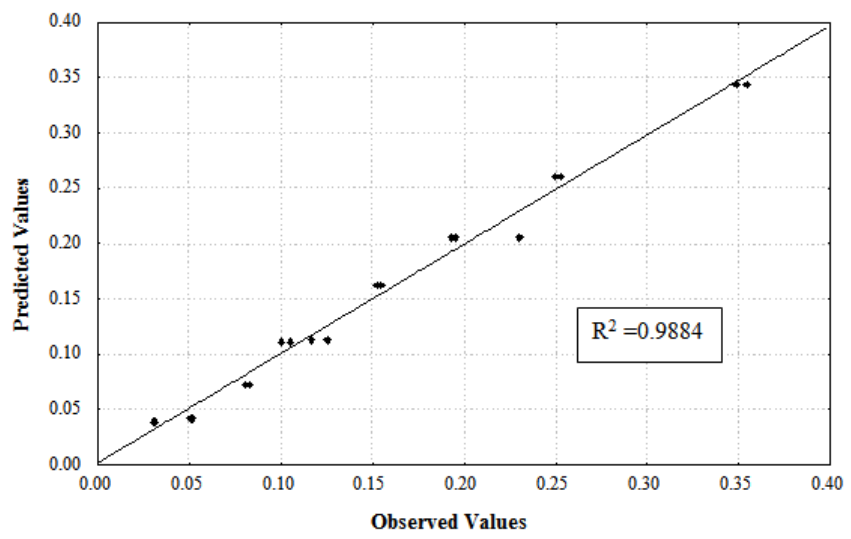

Figure 2. Parity plot showing the distribution of experimental versus predicted values by the mathematical model of the $Y_{p / s}$ values.

\section{Production of exopolysaccharides in bioreactors}

These experiments were conducted in a fermenter (Model BioFlow IV, New Brunswick Scientific), with 20 L capacity, equipped with disc impeller, oxygen and $\mathrm{pH}$ electrodes. The equipment also monitored temperature, agitation speed, gas purging flow rate, pumping rates, antifoam addition and the vessel level. All processing parameters were online monitored, with the aid of AFS 3.0 software (Advanced Fermentation Software, New Brunswick Scientific). The temperature $\left(30 \pm 1^{\circ} \mathrm{C}\right)$ and $\mathrm{pH}$ value $(7.0 \pm 0.1)$ were kept constant during the experiments. Other parameters, like substrate concentration, aeration and agitation, were chosen as the most significant ones, considering the experimental design. After selecting those parameters, experiments were done in duplicate, for 
Duta, F. P. et al.

Table 3. Results of the experimental design. Observed and predicted values.

\begin{tabular}{|c|c|c|c|c|c|}
\hline Experiments & $\boldsymbol{X}_{\mathbf{1}}$ & $\boldsymbol{X}_{\mathbf{2}}$ & $\boldsymbol{X}_{\mathbf{3}}$ & $\mathbf{Y}_{\mathrm{p} / \mathbf{s}}$ (g/g) Observed & Y $/ \mathbf{s}$ (g/g) Predicted \\
\hline 1 & 0.5 & 0.2 & 200 & $0.0305 \pm 0.0007$ & 0.0389 \\
\hline 2 & 1.0 & 0.2 & 200 & $0.1210 \pm 0.0056$ & 0.1126 \\
\hline 3 & 0.5 & 1.3 & 200 & $0.0815 \pm 0.0011$ & 0.0731 \\
\hline 4 & 1.0 & 1.3 & 200 & $0.2513 \pm 0.0020$ & 0.2596 \\
\hline 5 & 0.5 & 0.2 & 800 & $0.0507 \pm 0.0005$ & 0.0423 \\
\hline 6 & 1.0 & 0.2 & 800 & $0.1534 \pm 0.0019$ & 0.1118 \\
\hline 7 & 0.5 & 1.3 & 800 & $0.1023 \pm 0.0031$ & 0.3431 \\
\hline 9 & 1.0 & 1.3 & 800 & $0.3515 \pm 0.0037$ & 0.2064 \\
\hline
\end{tabular}

superior $(+)$ and lower (-) levels of the experimental design, and in triplicate, for the central point $(0)$.

For each experiment, $1000 \mathrm{~mL}$ of the inoculum was used, that is, $10 \%(\mathrm{v} / \mathrm{v})$ of the initial working volume $(10 \mathrm{~L})$. The process was conducted throughout $48 \mathrm{hrs}$.

\section{Analytical methods}

During the process, microscopic examinations, using Gram method, were performed in order to detect possible microbial contaminations in the medium.

Prior for the quantitative determination of mannitol, the fermented broth was filtered through $0.2 \mu \mathrm{m}$ Millipore membranes, in order to remove microbial cells. In the filtered fluid, the substrate was analyzed by high performance liquid chromatography (HPLC), in a Waters chromatograph, equipped with SHODEX SC1011 ionexchange columns, at $75^{\circ} \mathrm{C}$. Reagent water type I (ASTM, 2001) was used as eluent, and the elution rate applied was $0.8 \mathrm{~mL} / \mathrm{min}$.

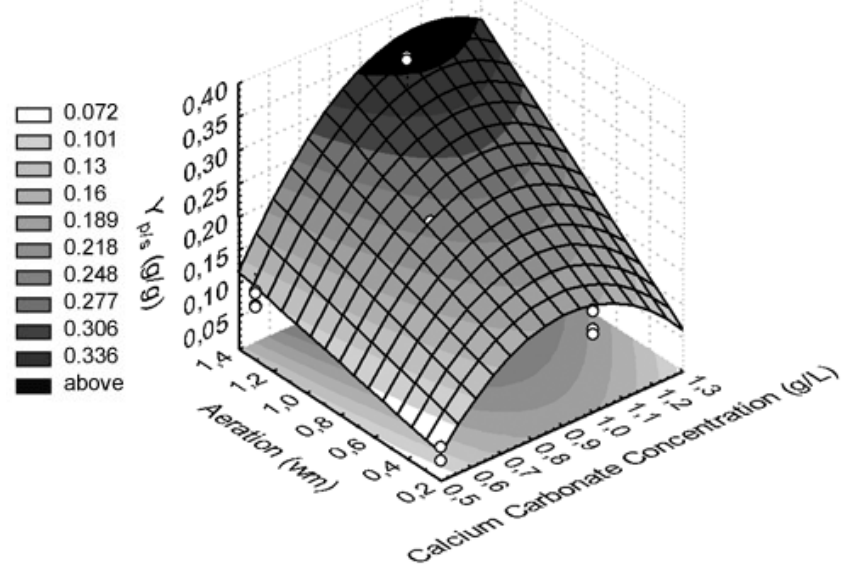

Figure 3. Effect of calcium carbonate concentration $\left(X_{1}\right)$ and aeration $\left(X_{2}\right)$ on the substratel exopolysaccharides factor, $Y_{p / s}$.

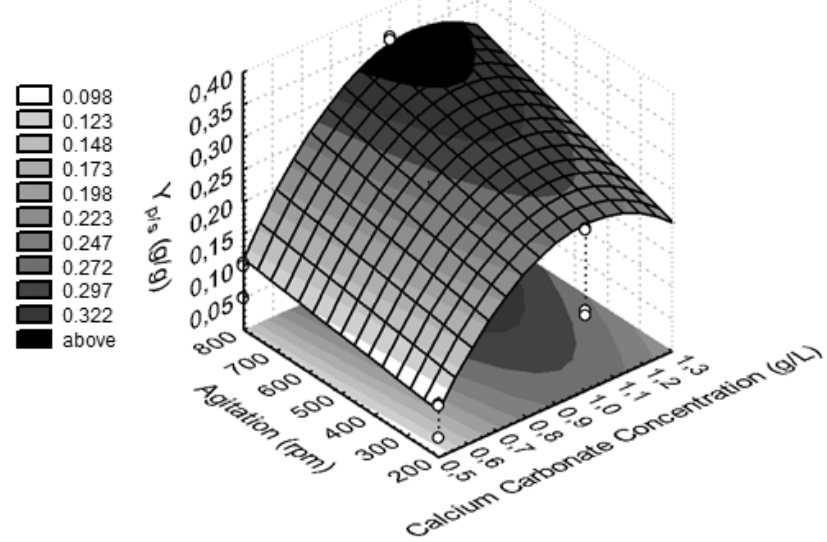

Figure 4. Effect of calcium carbonate concentration $\left(X_{1}\right)$ and aqitation $\left(X_{3}\right)$ on the substrate/exopolysaccharides factor, $Y_{n / s}$

The amount of fermented exopolysaccharide was determined by dry-weight measurements. The fermented broth was heated at $(80 \pm 1)^{\circ} \mathrm{C}$, for $10 \mathrm{~min}$, to ensure microbial inactivation. Afterwards, the microbial cells were removed by a filtration step. In order to precipitate the exopolysaccharides, a solution of ethanol P.A. and reagent water type I (ASTM, 2001) (3:1) was added to the fermented broth. After the exopolysaccharides total precipitation, the suspended material was filtered through $0.2 \mu \mathrm{m}$ Millipore membrane, using Gouche crucible previously weighed. The obtained product was dried at $(80$ $\pm 1)^{\circ} \mathrm{C}$ until constant weight. All determinations were done in triplicate.

The exopolysaccharides extracted from the fermented broth was purified through successive washings with solutions of ethanol P.A. and reagent water type I (ASTM, 2001) at 70, 80 and $90 \%(\mathrm{v} / \mathrm{v})$, respectively. The product was finally dried by a nitrogen gas purging flow, under controlled heating.

\section{Experimental design and statistical analysis}

This statistical technique is widely used as a tool to verify the efficacy of several processes. In the present work, it has been used for obtaining pieces of information about the 
Table 4. Results of regression analysis and corresponding $t$ and $p$-value of full second-order polynomial model for optimization of exopolysaccharides production of Rhizobium sp.

\begin{tabular}{|c|c|c|c|c|}
\hline Factor & Regression coefficient & Standard deviation & $\boldsymbol{t}$-statistic & $\mathbf{p}$-value \\
\hline$\beta_{0}$ & -0.361612 & 0.053958 & -6.70172 & 0.000054 \\
\hline$\beta_{1}(\mathrm{~L})$ & 1.147835 & 0.151855 & 7.55876 & 0.000019 \\
\hline$\beta_{11}(\mathrm{Q})$ & -0.714687 & 0.100544 & -7.10821 & 0.000033 \\
\hline$\beta_{2}(\mathrm{~L})$ & -0.081844 & 0.015520 & -5.27338 & 0.000361 \\
\hline$\beta_{3}(\mathrm{~L})$ & -0.000081 & 0.000027 & -2.96353 & 0.014202 \\
\hline$\beta_{1}(\mathrm{~L}) \times \beta_{2}(\mathrm{~L})$ & 0.205141 & 0.017367 & 11.81202 & 0.000000 \\
\hline$\beta_{1}(\mathrm{~L}) \times \beta_{3}(\mathrm{~L})$ & 0.000153 & 0.000032 & 4.80296 & 0.000720 \\
\hline$\beta_{2}(\mathrm{~L}) \times \beta_{3}(\mathrm{~L})$ & 0.000052 & 0.000014 & 3.58331 & 0.004984 \\
\hline
\end{tabular}

Legend: L: linear; Q: quadratic; $X_{1}$ : Calcium Carbonate Concentration; $X_{2}$ : Aeration; $X_{3}$ : Agitation; $\beta$ : terms coefficients.

exopolysaccharides production process; thus, a reduction in operational costs can be expected. A $2^{3}$ factorial planning, in duplicate, with central point in triplicate, was used (Box et al. 1978; Neto et al. 1995). Additionally, each experiment was repeated once, around the central point neighbourhood, while the central point was repeated twice, leading to a set of 19 experiments (Table 1). Three central points were added to estimate the experimental error and to investigate the suitability of the proposed model. Table 2 lists the independent variables studied, $X_{1}$ calcium carbonate concentration $(\mathrm{g} / \mathrm{L}), X_{2}$ aeration (vvm), $X_{3}$ agitation (rpm). The manipulation responses of the input variables were evaluated as a function of the substrate conversion into exopolysaccharide, coded by $\mathrm{Y}_{\mathrm{p} / \mathrm{s}}(\mathrm{g} / \mathrm{g})$.

A mathematical model, describing the relationships among the process dependent variable, $\mathrm{Yp} / \mathrm{s}$, and the independent variables in a second-order equation, was developed. Design-based experimental data were matched according to the following second-order polynomial equation:

$$
Y=\beta_{o}+\sum_{i=1}^{3} \beta_{i} X_{1}+\sum_{i=1}^{3} \beta_{i i} X_{i}^{2}+\sum_{i=1}^{3} \sum_{i \neq j} \beta_{i j} X_{i} X_{j}+\beta_{123} X_{1} X_{2} X_{3}
$$

where, $Y=$ substrate conversion into exopolysaccharides $\left(\mathrm{Y}_{\mathrm{p} / \mathrm{s}}\right)$,

$\beta_{0}=$ constant,

$\beta_{i}=$ linear terms coefficients,

$\beta_{i i}=$ quadratic terms coefficients,

$\beta_{i j}=$ interaction coefficients.

All the calculations involved as well as the drawing of all three-dimensional surface (3D) have been obtained using the Statistica ${ }^{\mathrm{TM}}$ Software for Windows, Version 5.5 computer package, produced by Stat Soft. The model allowed the evaluation of the effects of linear, quadratic and combined effects of the independents variables upon the variable dependent variable. The Student's $t$-test was employed in order to check the statistical significance of the regression coefficients. The Fisher's F-test for analysis of variance (ANOVA) was performed on experimental data to evaluate the statistical significance of the model.
Three-dimensional surface (3D) plots were drawn to illustrate the main and interactive effects of the independent variables on exopolysaccharides production. The optimum values of the selected variables were obtained both by solving the regression equation and also by analyzing the response surface contour plots (Myers and Montgomery, 2002).

\section{RESULTS AND DISCUSSION}

The statistical technique is widely used as a tool for checking the efficiency of several processes. In the present work it has been used with the purpose of obtaining information about the exopolysaccharides production process; consequently, a reduction in the operational variability and a cut down in operational costs can be expected.

The experimental results $\left(\mathrm{Y}_{\mathrm{p} / \mathrm{s}}\right)$, associated to the processing set up of each independent variables are listed in Table 3. Using the designed experimental data presented in Table 3, the polynomial proposed model for $\mathrm{Y}_{\mathrm{p} / \mathrm{s}}$ was regressed by only considering the significant terms. The expanded equation is shown below:

$\mathrm{Y}_{\mathrm{p} / \mathrm{s}}=-0.361612+\left(1.147835 X_{1}\right)+\left(-0.714687 X_{1}^{2}\right)+(-$ $\left.0.081844 X_{2}\right)+\left(-0.000081 X_{3}\right)+\left(0.205141 X_{1} X_{2}\right)+$ $\left(0.000153 X_{1} X_{3}\right)+\left(0.000052 X_{2} X_{3}\right)$

Besides the linear effect of the substrate/ exopolysaccharides factor, $Y_{p / s}$, the response surface method also gives an insight about the parameters quadratic and combined effects. These analyses were done by using both Fisher's F- test and Student $t$-test statistical tools. The student $t$-test was used to determine the significance of the parameters regression coefficients. The p-values were used as a tool to check the significance of the interaction effects, which in turn may indicate the patterns of the interactions among the variables. In general, larger magnitudes of $t$ and smaller of $p$, indicates that the corresponding coefficient term (Myers and Montgomery, 2002).

The regression coefficient, $t$ and $\mathrm{p}$ values for all the linear, 
quadratic and combined effects are given in the Table 4, with a $95 \%$ significance level. It was observed that the coefficients for the linear and quadratic effects of the factor calcium carbonate concentration parameter, the linear effect of the aeration parameter, the combined effects between calcium carbonate concentration with the aeration and agitation parameters $(\mathrm{p}=0.000$ for all) were highly significant. The value observed for the factor agitation was slightly less significant $(\mathrm{p}=0.014)$.

The statistical significance of the ratio, between the of mean square variation, due to regression, and the mean square residual error, was tested using analysis of variance (ANOVA). ANOVA is a statistical technique that subdivides the total variation of a set of data into component associated to specific sources of variation for the purpose of testing hypotheses for the modelled parameters. According to the ANOVA (Table 5), the Fvalues for all regressions were high, what indicates that most of the variations on the response variable can be explained by the regression equation. The associated $\mathrm{p}$ value is used to estimate whether $\mathrm{F}$ is large enough to indicate statistical significance. A p-value lower than 0.01 indicates that the model is considered to be statistically significant (Kim et al. 2003).

The $\mathrm{p}$ values of all of the regression were lower than 0.01 . This means that at least one of the terms in the regression equation has a significant correlation with the response variable. The ANOVA table also shows a term for residual error, which measures the amount of variation in the response data left unexplained by the model. The type of the model, chosen to explain the relationship between the factors and response, is correct.

The analysis of variance (ANOVA), indicates that the second-order polynomial model (Equation 1) was highly significant and adequate to represent the actual relationship between the response and input variables, with very small $p$ values $(p=0.0000)$.

Pareto chart (Figure 1) corroborates the data shown in
Table 5, and also enhances the understanding of this table. Figure 1 shows that all the linear terms of the model were significant for the set confidence level, as well as the quadratic term of $X_{1}$ variable (Table 5). It can also be seen that the interaction term among the three variables $\left(X_{1} X_{2} X_{3}\right)$, was not statistically significant (Figure 1 and Table 5). Statistical data analysis shows that calcium carbonateconcentration is the most important variable for the production process.

The matching quality, of the data obtained by the model proposed in Equation 1, was evaluated considering the correlation coefficient, $\mathrm{R}^{2}$, between the experimental and modelled data. The mathematical adjust of those values generated a $\mathrm{R}^{2}=0.9884$, revealing that the model could not explain only $1.16 \%$ of the overall effects, showing that it is a robust statistical model.

Figure 2 shows the regression plot of the $\mathrm{Y}_{\mathrm{p} / \mathrm{s}}$ experimental values against those predicted by Equation 1, revealing a linear mathematical relation among them. In addition, the mismatching analysis and further error terms found in Table 5, agree the adequacy of the predicted data, thus the reliability of the model proposed by Equation 1 .

The 3D response surface plots described by the regression model were drawn to illustrate the effects of the independent variables, and combined effects of each independent variable upon the response variable. Figure 3 illustrates 3D response surface based on the $Y_{p / s}$ response against the variation of calcium carbonate concentration $\left(X_{1}\right)$ and aeration $\left(X_{2}\right)$ independent variables upon $\mathrm{Y}_{\mathrm{p} / \mathrm{s}}$, while the third independent variable, agitation $\left(X_{3}\right)$, was kept constant level $(800 \mathrm{rpm})$. It can be observed that the maximum estimated $Y_{p / s} 0.3431(\mathrm{~g} / \mathrm{g})$ was obtained using calcium carbonate concentration of $1.0 \mathrm{~g} / \mathrm{L}$ and aeration of $1.3 \mathrm{vvm}$.

The data obtained by varying calcium carbonate concentration $\left(X_{1}\right)$ and agitation $\left(X_{3}\right)$, fixing aeration at 1.3 vvm, can be observed in Figure 4. The analysis of Figure 4 reveals that the maximum substrate conversion into

Table 5. Analysis of variance (ANOVA) for the fitted quadratic polynomial model for optimization of exopolysaccharides production of Rhizobium sp.

\begin{tabular}{|l|c|c|c|c|c|}
\hline Factor & $\begin{array}{c}\text { Sum of squares } \\
(\mathrm{SS})\end{array}$ & $\begin{array}{c}\text { Degrees of Freedom } \\
\text { (DF) }\end{array}$ & $\begin{array}{c}\text { Mean Square } \\
\text { (MS) }\end{array}$ & F-value & p-value \\
\hline$X_{1}(\mathrm{~L})$ & 0.093711 & 1 & 0.093711 & 1027.092 & 0.000000 \\
\hline$X_{1}(\mathrm{Q})$ & 0.004610 & 1 & 0.004610 & 50.527 & 0.000033 \\
\hline$X_{2}(\mathrm{~L})$ & 0.046428 & 1 & 0.046428 & 508.865 & 0.000000 \\
\hline$X_{3}(\mathrm{~L})$ & 0.007538 & 1 & 0.007538 & 82.620 & 0.000004 \\
\hline$X_{1}(\mathrm{~L}) \times X_{2}(\mathrm{~L})$ & 0.012730 & 1 & 0.012730 & 139.524 & 0.00000 \\
\hline$X_{1}(\mathrm{~L}) \times X_{3}(\mathrm{~L})$ & 0.002105 & 1 & 0.002105 & 23.068 & 0.000720 \\
\hline$X_{2}(\mathrm{~L}) \times X_{3}(\mathrm{~L})$ & 0.001172 & 1 & 0.001172 & 12.840 & 0.004984 \\
\hline Lack of fit & 0.001127 & 1 & 0.001127 & 12.353 & 0.005587 \\
\hline Pure error & 0.000912 & 10 & 0.000091 & & \\
\hline Total sum of squares & 0.170333 & 18 & & & \\
\hline
\end{tabular}

Legend: L: linear; Q: quadratic; $X_{1}$ : Calcium Carbonate Concentration; $X_{2}$ : Aeration; $X_{3}$ : Agitation. 
exopolysaccharides was also obtained under the following condition: at calcium carbonate concentration of $1.0 \mathrm{~g} / \mathrm{L}$ and agitation of $800 \mathrm{rpm}$.

Figure 3 and Figure 4 also show that an increase on agitation and aeration parameters promotes an increase on $\mathrm{Y}_{\mathrm{p} / \mathrm{s}}$. For each combination of agitation and aeration values, the model generates a maximum value for the concentration of calcium carbonate. Thus, for the maximum values used in the experimental design, $1.3 \mathrm{vvm}$ for the aeration and $800 \mathrm{rpm}$ for agitation, the predicted value for of calcium carbonate concentration is $1.1 \mathrm{~g} / \mathrm{L}$.

The application of the regression model (Equation 1) for the substrate/exopolysaccharides factor, $\mathrm{Y}_{\mathrm{p} / \mathrm{s}}$, was tested using calcium carbonate concentration of $1.1 \mathrm{~g} / \mathrm{L}$, agitation of $800 \mathrm{rpm}$ and aeration of $1.3 \mathrm{vvm}$, with triplicate experiments. For this experimental condition, $\mathrm{Y}_{\mathrm{p} / \mathrm{s}}$ mean value was of $0.3574 \pm 0.008448(\mathrm{~g} / \mathrm{g})$, which agrees with the predicted value, $0.3471(\mathrm{~g} / \mathrm{g})$. This verification revealed a high accuracy of the model, that is, $97.12 \%$, which is an evidence of the model validation, under the investigated conditions.

The process for exopolysaccharides production is carried out under aeration and agitation. The control of such parameters is of great importance for adequately conducting the fermentation process. According to Brock and Madigan (1991), for a rise in biomass from aerobic microorganisms, a vigorous aeration is required, what should be reached by forced aeration. This induced aeration is essential for getting high performance responses form the process, since oxygen is slightly soluble in water, not being quickly replaced by air diffusion, and worthwhile for microbial growth. Zevenhuizen (1986), using a mannitolrich culture medium, has directed the polysaccharide synthesis towards exopolysaccharides by applying forced aeration.

The efficiency in conducing forced aeration is linked to agitation, which favours oxygen diffusion in the medium and its transfer to cells. Agitation also promotes a reduction in nutrient particles, favouring the nutrient homogenization in the culture medium, providing additionally a rise in mass transfer rates, this favouring microbial growth.

In the production medium used for obtaining biopolymers, several ions are added to propitiate the exopolysaccharides, and these shall be in appropriate amounts. The metallic ions perform catalytic and essential structural functions in proteins, being accumulated inside the cell by active transport (Macció et al. 2002).

The literature tells about the use of calcium carbonate to prevent the acidification of the bacterial broth (Macció et al. 2002). Jordan (1984) suggested the use of $4.0 \mathrm{~g} / \mathrm{L}$ of calcium carbonate in the culture media, for controlling $\mathrm{pH}$ in the Rhizobium sp culture. O' Hara et al. (1989) previously reported that 1 and $2 \mathrm{mM}$ of calcium was necessary for cytoplasmic $\mathrm{pH}$ maintenance in Rhizobium meliloti acid-sensitive strain. The use of calcium ions can be intimately related to the stabilization of proteins involved in the exopolysaccharides synthesis process (Soto et al. 2004).

In agreement with the data presented in this study the yield income values of the product $\left(\mathrm{Y}_{\mathrm{p} / \mathrm{s}}\right)$, in a medium containing $1.0 \mathrm{~g} / \mathrm{L}$ of calcium carbonate was $0.35 \mathrm{~g} / \mathrm{g}$, in average. These results are consistent with the biochemical processes involving polymerization reactions forming high-viscosity products.

\section{CONCLUDING REMARKS}

Most researches developed using Rhizobium genus bacteria are related to genetics and bacteria-host plant symbiotic interactions issues. Little is known about the production of extra-cellular polysaccharides by Rhizobium, as well as their properties in solution. In addition, no studies on monitoring medium composition, agitation and aeration parameters effects, on exopolysaccharides production, were found.

The analysis of the response surfaces obtained by the experimental design, with central and having $\mathrm{Y}_{\mathrm{p} / \mathrm{s}}$ as response variable, shows the existence of a point of maximum production when agitation of $800 \mathrm{rpm}$, aeration of $1.3 \mathrm{vvm}$ and calcium carbonate concentration of $1.1 \mathrm{~g} / \mathrm{L}$ are applied.

The introduction of calcium carbonate, in the composition of the culture media, associated with high agitation and aeration, promoted a significant rise in the substrate/product yield $\left(\mathrm{Y}_{\mathrm{p} / \mathrm{s}}\right)$ (Duta et al. 2004).

Based on the present study, it is evident that the use of statistical optimization tools, response surface methodology, has helped to locate the optimum levels of the most significant parameters for exopolysaccharides production, with minimum effort and time.

\section{REFERENCES}

ABDEL-FATTAH, Yasser Refaat. Optimization of thermostable lipase production from a thermophilic Geobacillus sp. using Box-Behnken experimental design. Biotechnology Letters, July 2002, vol. 24, no. 14, p. 12171222.

ABDEL-FATTAH, Yasser Refaat and OLAMA, Zakia A. L-asparaginase production by Pseudomonas aeruginosa in solid-state culture: evaluation and optimization of culture conditions using factorial designs. Process Biochemistry, September 2002, vol. 38, no. 1, p. 115-122.

ABDEL-FATTAH, Yasser Refaat; SAEED, Hesham M.; GOHAR, Yousry M. and EL-BAZ, Mohamed A. Improved production of Pseudomonas aeruginosa uricase by 
optimization of process parameters through statistical experimental designs. Process Biochemistry, April 2005, vol. 40 , no. 5 , p. 1707-1714.

AMERICAN SOCIETY FOR TESTING MATERIAL (ASTM). Standard specification for reagent water. ASTM D-1193, October, 2001, p. 1-3.

BOHN, John A. and BEMILLER, James N. (1-3)-B-Dglucans as biological response modifiers: a review of strutucture-funcional activity relationships. Carbohydrate Polymers, January 1995, vol. 28, no. 1, p. 3-14.

BOX, G.E.P.; HUNTER, W.G. and HUNTER, J.S. Statistics for experimenters. An introduction to design, data analysis and model building. NY, USA. 1978. 653 p. ISBN 0-471-09315-7.

BREEDVELD, M.W.; ZEVENHUIZEN, L.P.T.M. and ZEHNDER, A.J.B. Excessive excretion of cyclic $\beta$ - $(1,2)-$ glucan by Rhizobium trifolii TA-1. Applied and Environmental Microbiology, July 1990, vol. 56, no. 7, p. 2080-2086.

BREEDVELD, M.W.; ZEVENHUIZEN, L.P.T.M.; CANTER CREMERS, H.C.J. and ZEHNDER, A.J.B. Influence of growth conditions on production of capsular and extracellular polysaccharides by Rhizobium leguminosarum. Antonie van Leeuwenhoek, March 1993, vol. 64 , no. 1 , p. 1-8.

BROCK, T.D. and MADIGAN, M.T. Biology of Microorganisms. New Jersey: Prentice-Hall International Editions, 6 ed., 1991. 874 p.

CAZETTA, M.L.; CELliGOI, M.A.P.C.; BUZATO, J.B.; SCARMINO, I.S. and DA SILVA, R.S.F. Optimization study for sorbitol production by Zymomonas mobilis in sugar cane molasses. Process Biochemistry, February 2005, vol. 40, no. 2, p. 747-751.

COPETTI, Giuliano; GRASSI, Mario; LAPASIN, Romano and PRICL, Sabrina. Synergic gelation of xanthan gum with locust bean gum: a rheological investigation. Glycoconjugate Journal, January 1997, vol. 14, no. 8, p. 951-961.

DUTA, Flávia Pereira; DA COSTA, Antonio Carlos Augusto; LOPES, Léa Maria De Almeida; BARROS, Ana; SÉRVULO, Eliana Flávia Camporese and de FRANÇA, Francisca Pessôa. Effect of Process Parameters on Production of a Biopolymer by Rhizobium sp. Applied Biochemistry and Biotechnology, April 2004, vol. 114, no. $1-3$, p. 639-652.

GORE, R.S. and MILLER, K.J. Cell surface carbohydrates of microaerobic, nitrogenase-active, continuous culture of Bradyrhizobium sp. strain 32H1. Journal of Bacteriology, December 1992, vol. 174, no. 23, p. 7838-7840.
JAGODZINSKI, Paul P.; WIADERKIEWICZ, Richard; KURZAWSKI, Grzegorz; KLOCZEWIAK, Marek; NAKASHIMA, Hideki; HYJEK, Elizabeth; Yamamoto, Naoki; URYU, Toshiyuki; KANEKO, Yutaro; POSNER, Marshall R. and KOZBOR, Danuta. Mechanism of the inhibitory effect of curdlan sulfate on HIV-1 infection in vitro. Virology, August 1994, vol. 202, no. 2, p. 735-745.

JAIN, D.K.; PREVOST, D. and BORDELEAU, L.M. Role of bacterial polysaccharides in the derepression of ex-planta nitrogenase activity with rhizobia. FEMS Microbiology Letters, February 1990, vol. 73, no. 2, p. 167-174.

JORDAN, D.C. Family III. Rhizobiaceae. In: KRIEG, N.R. and HOLT, J. G. eds. Bergey`s Manual of Systematic Bacteriology, Willians and Wilkins, Baltimore, vol. I, 1984, p. 234-342.

KHANNA, Shilpi and SRIVASTAVA, Ashok K. Statistical media optimization studies for growth and PHB production by Ralstonia eutropha. Process Biochemistry, May 2005, vol. 40, no. 6, p. 2173-2182.

KIM, H.O.; LIM, J.M.; JOO, J.H.; KIM, S.W.; HWANG, H.J.; CHOI, J.W. and YUN, J.W. Optimization of submerged culture condition for the production of mycelial biomass and exopolysaccharides by Agrocybe cylindracea. Bioresource Technology, July 2005, vol. 96, no. 10, p. 1175-1182.

KIM, H.M.; KIM, J.G.; CHO, J.D. and HONG, J.W. Optimization and characterization of UV-curable adhesives for optical communications by response surface methodology. Polymer Testing, December 2003, vol. 22, no. 8, p. 899-906.

LAKSHMAN, Kshama; RASTOGI, N.K. and SHAMALA, T.R. Simultaneous and comparative assessment of parent and mutant strain of Rhizobium meliloti for nutrient limitation and enhanced polyhydroxyalkanoate (PHA) production using optimization studies. Process Biochemistry, October 2004, vol. 39, no. 12, p. 1977-1983.

LEE, Kwang-Min and GILMORE, David F. Formulation and process modeling of biopolymer (polyhydroxyalkanoates: PHAs) production from industrial wastes by novel crossed experimental design. Process Biochemistry, January 2005, vol. 40, no. 1, p. 229-246.

LIU, Chuanbin; LIU, Yan; LIAO, Wei; WEN, Zhiyou and CHEN, Shulin. Application of statistically-based experimental designs for the optimization of nisin production from whey. Biotechnology Letters, June 2003, vol. 25 , no. 11 , p. 877-882.

MACCIÓ, Daniela; FABRA, Adriana and CASTRO, Stella. Acidity and calcium interaction affect the growth of Bradyrhizobium sp. and attachment to peanut roots. Soil Biology and Biochemistry, February 2002, vol. 34, no. 2, p. 
201-208.

MOREIRA, A. da S.; SOUZA, A. da S. and VENDRUSCOLO, Claire T. Determinação da composição de biopolímero por cromatografia em camada delgada: metodologia. Revista Brasileira de Agrociência, September-December 1998, vol. 4, no. 3, p. 222-224.

MYERS, R.H. and MONTGOMERY, D.C. Response surface methodology: process and product optimization using designed experiments. New York: Wiley, 2002. 824 p. ISBN 0-471-41255-4.

NAWANI, N.N. and KAPADNIS, B.P. Optimization of chitinase production using statistics based experimental designs. Process Biochemistry, February 2005, vol. 40, no. 2, p. 651-660.

NETO, B.B.; SCARMÍNIO, I. and BRUNS, R.E. Planejamento e otimização de experimentos, Editora UNICAMP, Campinas, Brasil, 1995.299 p. ISBN 8526803360 .

O' HARA, Graham W.; GOSS, Thomas J.; DILWORTH, Michael J. and GLENN, Andrew R. Maintenance of intracellular $\mathrm{pH}$ and acid tolerance in Rhizobium meliloti. Applied and Environmental Microbiology, August 1989, vol. 55 , no. 8 , p. $1870-1876$.

PINTO, Ellen; MOREIRA, Angelita and VENDRUSCOLO, Claire T. Influence of $\mathrm{pH}$, addition of salts and temperature in the viscosity of biopolimers produced by Beijerinckia sp. 7070 and UR4. Revista Brasileira de Agrociência, September-December 2002, vol. 8 , no. 3, p. 247-251.

RINAUDO, Marguerite. Relation between the molecular structure of some polysaccharides and original properties in sol and gel states. Food Hydrocolloids, July 2001, vol. 15, no. $4-6$, p. $433-440$.

SENTHILKUMAR, S.R.; ASHOKKUMAR, B.; RAJ, K. Chandra and GUNASEKARAN, P. Optimization of medium composition for alkali-stable xylanase production by Aspergillus fischeri Fxn 1 in solid-state fermentation using central composite rotary design. Bioresource Technology, August 2005, vol. 96, no. 12, p. 1380-1386.

SOTO, María José; VAN DILLEWIJIN, Pieter; MARTÍNEZ-ABARCA, Francisco; JIMÉNEZ-ZURDO, José I. and TORO, Nicolás. Attachment to plant roots and nod gene expression are not affected by $\mathrm{pH}$ or calcium in the acid-tolerant alfalfa-nodulating bacteria Rhizobium sp. LPU83. FEMS Microbiology Ecology, April 2004, vol. 48, no. 1, p. 71-77.

TANYILDIZI, M. Saban; OZER, Dursun and ELIBOL, Murat. Optimization of $\alpha$-amylase production by Bacillus sp. using response surface methodology. Process
Biochemistry, June 2005, vol. 40, no. 7, p. 2291-2296.

WANG, Yun-Xiang and LU, Zhao-Xin. Optimization of processing parameters for the mycelial growth and extracellular polysaccharide production by Boletus spp. ACCC 50328. Process Biochemistry, March 2005, vol. 40, no. 3-4, p. 1043-1051.

WEUSTER-BOTZ, Dirk. Experimental design for fermentation media development: statistical design or global random search? Journal of Bioscience and Bioengineering, September-October 2000, vol. 90, no. 5, p. 473-483.

ZEVENHUIZEN, L.P.T.M. Selective synthesis of polysaccharides by Rhizobium trifolli, strain TA-1. FEMS Microbiology Letters, June 1986, vol. 35, no. 1, p. 43-47. 